\section{Imparting reinforcing property to the taste of morphine through morphine injections*}

\author{
WAYNE R. COLISSENS \\ University of Mississippi. University, Miss. 38677
}

The present experiment tested the hypothesis that the taste of morphine would become a secondary reinforcer for rats made physically dependent on morphine by large, rapid intravenous injections. Rats made dependent by such injections and then withdrawn licked a dilute morphine solution more during a 30-sec licking period than did nondependent rats. A second experiment indicated that rats made physically dependent on morphine by 8 days of rapid injections licked a morphine solution more during withdrawal than did rats made dependent by 8 days of slow infusions. The results supported the preliminary hypothesis.

One procedure for studying opiate self-administration is the oral method, in which thirsty animals are allowed to drink dilute opiate solutions; then the amount consumed is measured and compared with the amount of nonopiate solutions consumed (Nichols, Headlee, \& Coppock, 1956, Thompson \& Ostlund, 1964; Kumar, Steinberg, \& Stolerman, 1968). With one variation of the method (Nichols et al, 1956; Nichols \& Davis, 1959; Davis \& Nichols, 1962), physical dependence is induced by repeated morphine injections prior to the drinking tests. Rats given such premedication followed by morphine deprivation "learned" to consume more $0.5 \mathrm{mg} / \mathrm{ml}$ morphine solution than water (Nichols et al, 1956).

Nichols has used his results to support a drive-reduction explanation of opiate abuse in humans and animals (Nichols, 1965). This explanation assumes that the drive state caused when physically dependent Ss are deprived of opiates is reduced by an opiate injection, and that the drive reduction reinforces the behavior preceding it. With the oral method, it is assumed that licking is the reinforced behavior. Nichols, Headlee, \& Coppock (1956) report that their Ss consumed an average of $78 \mathrm{cc}$ of morphine solution on the first day of training for morphine drinking. It is not clear, however, whether the

*This report is based on a thesis submitted to the Graduate School of the University of Mississippi in partial fulfillment of the requirements for the MA degree. The author is indebted to $\mathrm{Dr}$. William $F$. Crowder for his advice and consultation throughout the course of the investigation, as well as to Dr. J. B. Morris and Dr. B. G. Tate. This research was supported in part by U.S. Public Health Service Grant $M H 13570$ from the National Institute of Mental Health to Dr. William F. Crowder. Reprints may be obtained from Wayne R. Coussens, Department of Psychology, University of Mississippi. University, Miss. 38677. primary reinforcing conditions resulting from morphine drinking are sufficient to bring about such rapid learning. Morphine licking differs from that observed with less aversive substances in that, even under high deprivation, the behavior consists of short bursts of licking followed by long pauses, during which grooming and other behaviors occur. Such licking seems to cause a problem for a drive-reduction interpretation, since the reinforcing potency of morphine ingestion should be weak for two reasons. First, a delay occurs between morphine intake and its action in the blood. By the time the drive is reduced, the animal is probably doing something other than drinking, e.g., grooming or eating, and these behaviors should be reinforced. Second, since only about $0.0015 \mathrm{mg}$ of morphine is consumed in a single enough morphine is ingested to reinforce licking through reduction of the drive. It is unlikely, therefore, that morphine licking is acquired solely on the basis of such drive reduction.

Since conditioning is rapid and since it is probably not due to primary drive reduction, it seems that the licking must be maintained through a secondary reinforcer. For the same reasons that the primary reinforcer should not maintain licking, it is unlikely that a powerful secondary reinforcer could become established well enough in the first training session to provide immediate reinforcement. If the secondary reinforcing properties could somehow be acquired before the animal ever drinks morphine, this problem would not exist.

"Intravascular taste" may be one way that the taste of morphine could acquire a secondary reinforcing property without the animal's ever drinking morphine. The "intravascular taste system" was demonstrated (Bradley \& Mistretta, 1971) when rats made "sick" following an intravenous lick, many licks are necessary before infusion of saccharin drank less saccharin solution in a choice test with water than control rats. During the buildup of physical dependence, morphine injections could conceivably impart secondary reinforcing properties to morphine's taste through the intravascular taste system. If morphine in the blood stimulates taste receptors, this stimulation would be paired with drive reduction and would thus become a secondary reinforcer for morphine licking. Such reinforcement would be detectable on the first occasion for morphine licking after pairings of taste (through injections) and drive reduction.

\section{EXPERIMENT 1}

The purpose of Experiment 1 was to determine whether injections which build up physical dependence could impart secondary reinforcing property to the taste of morphine. The experiment was conducted in two phases: physical dependence and morphine drinking during drug withdrawal. If rats made physically dependent by repeated morphine injections drink a morphine solution rapidly upon its first presentation, the hypothesis of secondary reinforcement would be supported and could possibly resolve the problem presented by a drive-reduction interpretation of oral opiate self-administration. Drive reduction might still be crucial to oral self-administration, but the essential reduction of drive would take place during buildup of physical dependence rather than after the animal drinks morphine.

The Ss were 39 male Sprague-Dawley strain rats, approximately 90 to 100 days oid. The rats were individually housed and had food and water available at all times. Each rat had a chronic polyethylene jugular cannula. The Ss were assigned randomly to two groups, 27 to the experimental group and 12 to the control group. As a result of death during the injection period and during withdrawal, leaking catheters, apparatus failure, and nonwater satiation, only 8 experimental and 9 control rats finished the experiment. Apparatus

Licking behavior was recorded on a Brush Series RD 2522 two-channel recorder connected to a glass drinking tube and the animal's cage. Licks were recorded when an animal, standing on the cage floor, completed the circuit by licking a solution in the drinking tube. In order to record the individual licks, the recorder tape speed was set at $25 \mathrm{~mm} / \mathrm{sec}$.

Procedure

On Day 1 of the acquisition phase, all Ss received a $150-\mathrm{mg} / \mathrm{kg}$ intravenous (IV) injection of $50 \mathrm{mg} / \mathrm{ml}$ 
morphine sulfate solution at 8 a.m. and at 8 p.m. Immediately before each morphine injection, the experimental Ss received a randomly selected number of $0.25-\mathrm{ml}$ saline injections, the number of such injections being 0 , $1,2,3$, or 4 . This procedure was used so that the morphine taste, rather than the stimulation from the injection itself, would be associated with the physiological effects of the morphine. All infusions were manual, and their speed was held constant at approximately $1 \mathrm{ml} / 20 \mathrm{sec}$.

On succeeding days, the injection procedure was the same as on Day 1 , except that the morphine dosage was increased in the following progression: $200,250,300,350$, and $400 \mathrm{mg} / \mathrm{kg}$ per infusion. The last dosage, $400 \mathrm{mg} / \mathrm{kg}$, was repeated on Days 7,8 , and 9 , with a single injection being given at 2 p.m. The single-injection procedure was intended to provide pairings of morphine taste and withdrawal relief. Control Ss received the same treatment as experimental Ss throughout the experiment, except that equal volumes of physiological saline were substituted for morphine.

The testing phase was conducted in the home cage on Day 11 of the experiment, approximately 40-48 h after the last morphine injection. All Ss had water available at all times prior to testing and were considered water satiated. As soon as each $\mathbf{S}$ began to lick, its water bottle was removed. The $S$ was tested immediately for morphine licking: the test substance, a $0.5-\mathrm{mg} / \mathrm{ml}$ morphine sulfate solution, was presented, the recorder was started, and licking was recorded for $30 \mathrm{sec}$ after the initial licking response. Results

The number of licks for each $\mathrm{S}$ over the 30-sec licking period was taken from the graphic records. The mean number of licks for the morphine-injected $\mathrm{Ss}$ and for the saline-injected Ss were 34.13 and 19.22, respectively. These means differed significantly by the $t$ test $(t=$ 2.22, $\mathrm{df}=15, \mathrm{p}<.025$ )

EXPERIMENT 2

The results of Experiment 1 tend to support an interpretation that stimulation of the taste receptor, resulting from large, rapid intravenous morphine injections and paired with withdrawal reduction, can become a secondary reinforcer for morphine licking. However, the greater morphine licking of the experimental group could have been due to the physical dependence of the $S s$ and not to the rapid morphine infusion alone. Similar results might have been obtained with Ss receiving buildup of physical dependence by slow infusion.

The purpose of Experiment 2 was to determine whether morphine pretreatment alone could account for differences in morphine licking in Experiment 1. Rapidly injected experimental rats, similar to those of Experiment 1, and rats receiving slow morphine infusions were equated on amount of morphine received for buildup of physical dependence. The slow infusions should have prevented the development of secondary reinforcement for two reasons: (1) morphine concentration in the blood was low and therefore, presumably, could not be tasted; (2) drive reduction was too slow to be a powerful reinforcer. If rats made physically dependent by slow infusion exhibited the same morphine licking as rats receiving rapid injections, the Experiment 1 results might have been due to physical dependence alone.

The experiment was conducted in two phases, as in Experiment 1: physical dependence and morphine licking following withdrawal.

$$
\text { Subjects }
$$

The Ss were 21 male Sprague-Dawley strain rats, approximately 90 to 100 days old. The rats were individually housed with food and water available at all times. Each rat had a chronic polyethylene jugular cannula, as in Experiment 1. One experimental $S$ and 4 control $S$ died during buildup of physical dependence. Four additional cannulated rats of the same age, sex, and strain were used in a supplementary test.

\section{Apparatus}

During buildup of physical dependence for the control groups, infusion pumps, operated for $1 \mathrm{sec}$ every 20 sec by a timer, delivered a 0.0056-cc morphine infusion to the Ss. The morphine solution was delivered to each rat's cannula through a flexible leash constructed of 18-ga needle tubing, vinyl tubing, and silicone rubber tubing.

During testing, the Brush recorder circuit and glass drinking tube were used, as in Experiment 1.

\section{Procedure}

On Day 1 , Ss were assigned randomly to four groups, differing only in the number of days morphine was received and the speed of the infusion during buildup of physical dependence. The Ss were either rapidly injected (given their doses of morphine in $2-3 \mathrm{~min}$ ) or slowly infused (given their dose of morphine slowly over $3 \mathrm{~h}$ ). The four groups were as follows: (1) rapidly injected for 8 days (Group $R 8, N=4$ ); (2) rapidly injected for 4 days (Group $R 4, N=4$ ); (3) slowly infused for 8 days (Group S8; N=5); and (4) slowly infused for 4 days (Group $S 4 ; N=3$ ).

Buildup of physical dependence for Group R8 was identical to that of the experimental group of Experiment 1 . Group R4 received the same treatment, except that fewer days of injection were given. That is, Group R4 received two $150-\mathrm{mg} / \mathrm{kg}$ morphine injections on Day 1 , two $200-\mathrm{mg} / \mathrm{kg}$ injections on Day 2 , two $250-\mathrm{mg} / \mathrm{kg}$ injections on Day 3 , and a single $250-\mathrm{mg} / \mathrm{kg}$ injection on Day 4 . Group $S 8$ received the same treatment as Group R8, and Group S4 received the same treatment as Group R4, except that for Groups S8 and S4, each morphine dosage was administered as 540 injections of a p proxim a te 1 y 0.0056 cc automatically infused, one every $20 \mathrm{sec}$ for $3 \mathrm{~h}$. The infusions began at 8 a.m. and at 8 p.m.

Following buildup of dependence, each group was withdrawn for $30 \mathrm{~h}$. licking behavior was assessed as in Experiment 1, with each $S$ being tested in its home cage.

A further test was conducted to determine if the four groups of dependent rats differed from one another in observable withdrawal symptoms, and if they differed from a fifth group consisting of nondependent rats. If the dependent groups differed in withdrawal, differences in morphine licking might be due to the withdrawal differences. Three graduate student volunteers, who were naive as to the symptoms of withidrawal, served as judges. Their duty was to rank the rats on the degree of withdrawal exhibited. The judges were given both written and oral descriptions of the withdrawal symptoms to be observed. The symptoms described were "wet dog" shakes, ptosis, yawning, high activity, aggressiveness toward the handler, squealing with the back is touched, and writhing.

The judges were instructed to rank the Ss from 1 to 20 , giving a rank of 1 to the $S$ showing the most severe withdrawal and a rank of 20 to the $S$ showing the least withdrawal. Any questions concerning the symptoms or the task were answered prior to the beginning of ranking. The three judges worked individually, and each was allowed $\mathbf{3 0} \mathrm{min}$ to complete the task. The rats were ranked under approximately $36 \mathrm{~h}$ withdrawal.

\section{Results}

A 2 by 2 analysis of variance was conducted on the number of licks made by each group during the test period. The rapidly injected groups licked significantly more than the slowly infused groups $(\mathrm{F}=7.57, \mathrm{df}=$ $1 / 12, p<.05)$, No significant differences were found, however, between licking for 4- and 8-day dependence groups $(F=1.15, \mathrm{df}=$ $1 / 12, p>.05$ ), and no interaction was found $(F=2.88, \mathrm{df}=1 / 12, \mathrm{p}>.05)$. 
Scheffé's multiple comparison test was applied to each set of two means. The mean for Group R3 was significantly greater than both the mean for Group S8 $(t=3.75, \mathrm{df}=12, \mathrm{p}<.01)$ and the mean for Group S4 $(t=2.63$, df $=12, p<.05$ ), but not the mean for Group $R 4(t=2.0, d f=12$, $p>, 05$ ). Groups $\mathrm{R} 4, \mathrm{~S} 8$, and $\mathrm{S} 4 \mathrm{did}$ not difier significantly among themselves.

A mean of the three Os' rankings during the supplementary test was calculated for each $\mathrm{S}$. An analysis of variance was conducted on the mean withdrawal rankings of $S s$ in the four physically dependent groups. No significant differences were found between the mean rankings for the four groups, indicating that differences in degree of withdrawal could not account for the Experiment 2 results $(F=1.73, \mathrm{df}=3 / 12, \mathrm{p}>.05) . \mathrm{O}$ reliability was not determined for rankings, and, therefore, it is conceivable that this lack of differences could be due to low reliability.

A Mann-Whitney $U$ test was conducted on the mean Os' rankings between the nonphysically dependent group and each of the four physically deptendent groups. In each of the four cases, a U of zero was obtained (ps $<.028$ ), In other words, every rat in the four physically dependent groups was ranked higher than any rat in the nonphysically dependent group. DISCUSSION

The main purpose of the present study was to determine if the taste of morphine could become a secondary reinforcer for morphine drinking through pairings with withdrawal reduction during the buildup of physical dependence. The principal finding of the two experiments was that rats made physically dependent by large, rapid morphine injections for 8 days licked a morphine solution substantially more during withdrawal than either nondependent, saline-injected control $S s$ or Ss made physically dependent on morphine by slow infusions for 8 days. These licking differences could not be due to primary reinforcement from drive reduction, since the rats licked for only 30 sec. This finding tends to support the secondary reinforcement hypothesis.

That Group R4 did not lick significantly more than Groups $\mathrm{S} 4$ and S8 suggests that the number of pairings received was not large enough for secondary reinforcement to develop. Ss in Group R4 showed licking well below that of $S s$ in Group R8 and at approximately the same level as those in both Group S8 and Group S4. That one $S$ in Group R4 licked more than any of the slowly infused Ss and more than any but one $S$ in Group $R 8$ might lead one to speculate that taste could acquire secondary reinforcing properties for some animals with as few as two or three pairings.

It appears from the results of the present study that the taste of morphine can develop secondary reinforcing properties in the buildup of physical dependence. The development of such secondary reinforcement could explain the results of Nichols, providing it can be shown that intravascular taste can occur following intraperitoneal injections, as used by Nichols. Plans have been made for a study, comparable to the present one, using intraperitoneal injections in the buildup of physical dependence.

\section{REFERENCES}

BRADLEY, R. M., \& MISTRETTA, C. M. Intravascular taste in rats as demonstrated by conditioned aversion to sodium saccharin. Journal of Comparative \& Physiological Psychology, 1971, 75, 186-189.

DAVIS, W. M., \& NICHOLS, J. R. Physical dependence and sustained opiate-directed behavior in the rat. Psychopharmacologia. $1962,3,139-145$.

KUMAR, R., STEINBERG, H., \& STOLERMAN, I. P. Inducing a preference for morphine in rats without premedication. Nature, 1968,218 , 564-565.

NICHOLS, J, R. How opiates change behavior. Seientific American, 1965, 212 , 80-88.

NICHOLS, J. R., \& DAVIS, W. M. Drug addiction: II. Variation of addiction. Journal of the American Pharmacological Association (Sci. ed.), 1959, 48, 259-262.

NICHOLS, J. R., HEADLEE, C. P., \& COPPOCK, H. W. Drug addiction: $I$. Addiction by escape training. Journal of the American Pharmacological Association (Sci. ed.), 1956, 45, 788-791.

THOMPSON, T \& OSTLUND, $W$ JR. Susceptibility to readdiction as a function of the addiction and withdrawal environment. Reports from the Laboratories of the Department of Psychiatry, University of Minnesota, 1964, Report No. RP-64-2. 